\title{
Carboxymethyl Glucomannan from Amorphophallus oncophyllus as an Alternative Heavy Metal Removal from Wastewater: Adsorption of Cadmium and Zinc
}

\author{
Hikmat $^{*}$, Renta Resdiana ${ }^{2}$, Aprilia Nur Tasfiyati ${ }^{1}$ \\ 'Research Center for Chemistry, Indonesian Institute of Sciences, Serpong, Tangerang Selatan 15314, \\ Indonesia \\ ${ }^{2}$ Energy Conversion Engineering Department, Bandung State Polytechnic, Ciwaruga, Bandung 40012, \\ Indonesia
}

"Corresponding author email: hikmat@lipi.go.id; hikmat.lipi@gmail.com

Received July 15, 2020; Accepted November 24, 2020; Available online March 25, 2021

\begin{abstract}
Carboxymethyl glucomannan (CMGM) was successfully synthesized through the reaction of glucomannan from Amorphophallus oncophyllus and monochloroacetic acid, using $\mathrm{NaOH}$ as a catalyst. Two types of glucomannan were used in this study, low viscosity glucomannan (LGM) and high viscosity glucomannan (HGM). The produced CMGM were differentiated into LCMGM (synthesized from LGM) and HCMGM (synthesized from HGM). The CMGM structure was characterized by FTIR, and the degree of substitution (DS) was determined using back titration method. The DS value were 0.484 and 0.412 for LCMGM and HCMGM, respectively. Both CMGMs were then evaluated for its adsorption capacity towards $\mathrm{Zn}$ and $\mathrm{Cd}$ at the optimum $\mathrm{pH}$ of 6 , with 60 minutes adsorption time for each sample. The maximum adsorption capacity of Zn was $13.61 \mathrm{mg} / \mathrm{g}$ and $13.04 \mathrm{mg} / \mathrm{g}$ for LCMGM and HCMGM, respectively. While for Cd, the maximum adsorption capacity of LCMGM and HCMGM was $17.70 \mathrm{mg} / \mathrm{g}$ and $15.90 \mathrm{mg} / \mathrm{g}$. The adsorption capacity of the sample follows the Langmuir isotherm adsorption. In conclusion, CMGM from A. oncophyllus has demonstrated its potential as a reusable adsorbent for efficient removal of $\mathrm{Cd}$ and $\mathrm{Zn}$.
\end{abstract}

Keywords: adsorption; Amorphophallus oncophyllus; carboxymethyl glucomannan; heavy metal

\section{INTRODUCTION}

Wastewater from various industries such as metal plating, fertilizer, pesticide, paint, battery, mining, and metal processing industries generally contains heavy metals such as $\mathrm{Pb}, \mathrm{Cd}, \mathrm{Cu}, \mathrm{Zn}$, and $\mathrm{Hg}$ (Jobby, Jha, Yadav, \& Desai, 2018; Yadav, Gadi, \& Kalra, 2019). Unlike most of organic waste that can be naturally degenerated, heavy metals cannot be degraded in nature. Direct disposal of waste containing heavy metals can damage the environment, highly toxic, and can accumulate in organisms and human body (Huang et al., 2017; Roney et al., 2006; Sud, Mahajan, \& Kaur, 2008). Heavy metals can also enter human body over the food chain, which may cause poisoning and damage to body tissues, leading to severe health issues such as anemia, emphysema and hypertension (Jain, Johnson, Kumar, Mishra, \& Gupta, 2015). Zinc poisoning also contributes to the inhibition of electron transport chain (Mangold, Potrykus, Björn, Lövgren, \& Dopson, 2013).

A number of methods have been developed to reduce heavy metal contamination in waters, i.e. coagulation and flocculation, membrane filtration, ion exchange, and adsorption (Fu \& Wang, 2011; Salah, Mohammad, Hassan, \& El-Anadouli, 2014;
Zawierucha, Kozlowski, \& Malina, 2016; Zewail \& Yousef, 2015). Of these methods, the development of natural polymer adsorbents for heavy metal adsorption has attracted much attention. Natural polymer adsorbents can be derived from microbial, algae, and agricultural products (Mukheriee \& Halder, 2018). The utilization of agricultural products to remove heavy metals in water samples is based on metal biosorption. Biosorption methods for metal removal applications have several advantages, including low cost, highly efficient, renewable, and biodegradable (Sud, Mahajan, \& Kaur, 2008; Wan Ngah \& Hanafiah, 2008). One of the agricultural products that can be employed as biosorbent is glucomannan.

Glucomannan is a water-soluble natural heteropolysaccharide that has a $\beta-1,4$ bond between $D$ mannose and D-glucose, with a molar ratio of 1.6:1 (Behera \& Ray, 2017). Glucomannan is a polysaccharide that is very abundant in nature, especially in woody plants, roots, and tubers (AlonsoSande, Teijeiro-Osorio, Remuñán-López, \& Alonso, 2009; Chua et al., 2012). Glucomannan has a molecular weight of 200,000-2,000,000 Dalton with a size of $0.5-2 \mathrm{~mm}$ (Parry, 2010). A reasonably high 
source of glucomannan in Indonesia is porang plant (Amorphophallus oncophyllus), which is a local perennial plant commonly found in forest. The characteristics of glucomannan extracted from Porang is significantly different from the konjac glucomannan. It has higher degree of acetylation and solubility, but lower viscosity, degree of polymerization and water holding capacity compared to commercially available konjac glucomannan (Harmayani, Aprilia, \& Marsono, 2014). Other than being a food ingredient, glucomannan can also be used as a biosorbent of toxic compounds and metals (Battacone, Carboni, Nicolussi, Ligios, \& Pulina, 2007).

In the application of glucomannan as a metal biosorbent, various modifications to the structure of glucomannan have been developed to increase its ability to adsorb metal. Liu et al. reported the preparation of modified konjac glucomannan by grafting acrylic acid onto deacetylated konjac glucomannan (GADKGM) for $\mathrm{Zn}^{2+}$ removal from aqueous solution, with adsorption capacity of 125 $\mathrm{mg} / \mathrm{g}$ (Liv, Luo, \& Lin, 2009). Another modification of glucomannan, in the form of carboxylic acid functionalized deacetylated konjac glucomannan (CADKGM), was also studied for the adsorption of $\mathrm{Cu}^{2+}$ and $\mathrm{Pb}^{2+}$ ions (Liu, Luo, Lin, Liang, \& Chen, 2009; Luo, Liu, Deng, \& Lin, 2011). The study revealed that the maximum removal efficiency for both ions was found to be $98-99 \%$, with maximum uptake capacity of $\mathrm{Cu}^{2+}$ and $\mathrm{Pb}^{2+}$ ions were $64.5 \mathrm{mg} / \mathrm{g}$ and $191.3 \mathrm{mg} / \mathrm{g}$, respectively.

A biodegradable konjac glucomannan-poly(acrylic acid) (KGMP) hydrogel was prepared by grafting konjac glucomannan with acrylic acid. The adsorbent was then tested to remove $\mathrm{Cu}^{2+}$ ions from aqueous solution, with adsorption capacities of $27.1739 \mathrm{mg} / \mathrm{g}$ (Chen, Zhang, \& Li, 2016). Graphene oxide was also employed to modify konjac glucomannan forming a three-dimensional network structure of konjac glucomannan/graphene oxide (KGM/GO) sponges. The performance of KGM/GO was tested against $\mathrm{U}(\mathrm{VI})$, and it showed excellent selectivity with maximum adsorption capacities of $266.97 \mathrm{mg} / \mathrm{g}$ (Chen et al., 2018). Another study by Mao et al. reported the preparation of amphiprotic-konjac glucomannan/ chitosan (AP-KGM/CS) aerogels, with adsorption capacities of $469 \mathrm{mg} / \mathrm{g}, 254 \mathrm{mg} / \mathrm{g}$ and $144 \mathrm{mg} / \mathrm{g}$, for $\mathrm{Pb}^{2+}, \mathrm{Cu}^{2+}$, and $\mathrm{Cd}^{2+}$, respectively (Mao et al., 2019).

Carboxymethyl glucomannan (CMGM) is one of glucomannan derivatives, produced from the reaction between glucomannan and monochloroacetate, using $\mathrm{NaOH}$ as a catalyst (An, Dong, Dung, \& Thien, 2011; Kobayashi, Tsujihata, Hibi, \& Tsukamoto, 2002; Wang, Zhu, Xu, Qiao, \& Zhang, 2011). CMGM has desirable characteristics suitable for a metal biosorbent. It has negative charge that enable the interaction with positively charged metal ions, as well as high stability and water solubility (Alonso-Sande ef al., 2009; Xia et al., 2010). CMGM has been reported as a renewable, biodegradable and effective adsorbent for a number of heavy metals from aqueous solutions, i.e. $\mathrm{Cd}, \mathrm{Cu}, \mathrm{Hg}, \mathrm{Pb}$, and $\mathrm{U}$ (Chen et al., 2017; Liang et al., 2020; Liu, Zhang, \& Wang, 2011; Niu, Li, \& Huang, 2011; Niu, Wu, Wang, Li, \& Wang, 2007).

While the application of CMGM derived from konjac glucomannan as a metal biosorbent has been extensively studied, the use of CMGM from Porang plant ( $A$. oncophyllus) has never been reported. In addition, the metal adsorption capacity of $\mathrm{Zn}^{2+}$ and $\mathrm{Cd}^{2+}$ in both glucomannan and carboxymethyl glucomannan have not been much studied yet. This article will report firstly on the synthesis and characterization of carboxymethyl glucomannan using glucomannan extracted from $A$. oncophyllus. The glucomannan employed in this study are low and high viscosity types of commercially available Porang glucomannan, that have different level of glucomannan. The adsorption capacity of both glucomannan and carboxymethyl glucomannan produced in this study were evaluated against $\mathrm{Zn}^{2+}$ and $\mathrm{Cd}^{2+}$. The performance of both low and high viscosity types of glucomannan and carboxymethyl glucomannan were also investigated in this study.

\section{EXPERIMENTAL SECTION \\ Materials and instrumentation}

Two types of glucomannan powder used in this study were obtained from CV. Sanindo Putra (Bandung, Indonesia). Those are low viscosity glucomannan (LGM) and high viscosity glucomannan (HGM), with glucomannan levels of $25.93 \%$ and $21.41 \%$, respectively. The chemicals used in this study were monochloroacetic acid, sodium hydroxide, hydrochloric acid, ethanol, zinc nitrate, cadmium nitrate, and nitric acid. All chemicals used were of analytical grade, purchased from Merck KGaA (Darmstadt, Germany).

The resulting CMGMs were characterized by FTIR spectrophotometer (Shimadzu Prestige 21), while the analysis of $\mathrm{Cd}$ and $\mathrm{Zn}$ were performed using Atomic Absorption Spectrometer (AAS) (GBC SavantAA).

\section{Synthesis of Carboxymethyl Glucomannan}

The synthesis of CMGM was following the procedure described by An et al. (2011) with minor modifications. A gram of each glucomannan powder, was dissolved in $100 \mathrm{~mL}$ distilled water and mixed with a magnetic stirrer. Then, the $\mathrm{pH}$ of the mixture was adjusted to 10 by adding $10 \% \mathrm{NaOH}$. Two grams of monochloroacetic acid was then added gradually to the mixture, while maintaining the $\mathrm{pH}$ of the mixture around 9-10. The mixture then subsequently heated to $60{ }^{\circ} \mathrm{C}$ for 3 hours, filtered, and cooled down. Afterwards, the $\mathrm{pH}$ of the filtrate was adjusted to $\mathrm{pH} 5$ with $1 \%$ hydrochloric acid, to promote the formation of CMGM precipitate. The precipitate was then filtered, washed with $90 \%$ ethanol, and dried at $60^{\circ} \mathrm{C}$ until a constant weight is achieved. 
The resulting CMGM were differentiated into LCMGM (synthesized from low viscosity glucomannan /LGM) and HCMGM (synthesized from high viscosity glucomannan / HGM).

\section{Characterization}

The characterization of both glucomannan and CMGM was performed using Fourier Transform Infrared (FTIR) spectrophotometer. The degree of substitution (DS) was determined using back titration method as reported by Stojanovic et al. (Stojanović, Jeremić, Jovanović, \& Lechner, 2005).

\section{Metal Adsorption}

Metal solutions were prepared by dissolving metal salts in distilled water. The $\mathrm{pH}$ of the resulting metal solutions was then adjusted to various $\mathrm{pH}$ value from 3 to 7 using $\mathrm{NaOH} 1 \mathrm{M}$ and $\mathrm{HCl} 1 \mathrm{M}$. Each type of glucomannan and CMGM solutions were individually prepared by dissolving 0.1 grams of powder in $50 \mathrm{~mL}$ distilled water, followed by stirring until a homogenous solution is achieved.

The metal solutions that have been previously prepared were then added to the glucomannan and CMGM solution with the ratio of $1: 4$, while continuously stirring over a period of time ranging from 0 to $120 \mathrm{~min}$, to evaluate the effect of contact time towards adsorption capacity. The mixtures were then centrifuged at $1000 \mathrm{rpm}$ for $30 \mathrm{~min}$ under ambient temperature and filtered. Finally, the filtrate was subjected to Atomic Absorption Spectrophotometer (AAS) analysis for the determination of non-adsorbed metal ion.

\section{Metal Desorption}

Metal solutions were added separately to glucomannan and CMGM solutions, with the ratio of $4: 1$, as described in section 2.4 , followed by stirring

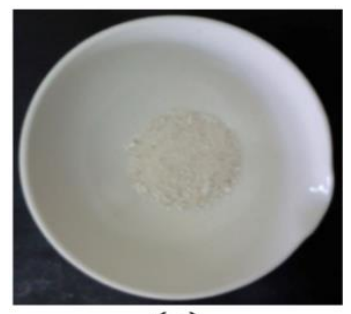

(a)

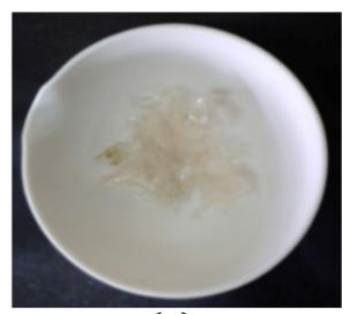

(c) with a magnetic stirrer. The resulting mixtures were then centrifuged and filtered. The filtrate then analyzed by AAS to measure the non-adsorbed metal ion. The metal-binding residue was placed in a desorption medium (0.1 M nitric acid) and agitated with a speed of $1000 \mathrm{rpm}$ for 30 minutes at room temperature to release the metal ion into solution. The solutions were also subjected to AAS to quantify metal ion concentration.

\section{RESULTS AND DISCUSSION}

\section{Synthesis of Carboxymethyl Glucomannan}

Two types of glucomannan powder extracted from Porang plant (A. oncophyllus) were obtained from CV. Sanindo Putra (Bandung, Indonesia), as shown in Figure 1 (a) and (b). Low viscosity glucomannan (LGM) has glucomannan levels of $25.93 \%$, while high viscosity glucomannan (HGM) contain $21.41 \%$ of glucomannan. CMGM was synthesized from glucomannan following the procedure described by An et al. (An et al., 2011). The addition of $\mathrm{NaOH}$ during carboxymethylation reaction at an elevated temperature of $60{ }^{\circ} \mathrm{C}$, can trigger the hydration of glucomannan. In addition, higher stirring rate and reaction temperature will also speed up the carboxymethylation reaction.

The resulting CMGMs were differentiated into two types according to the type of glucomannan used during synthesis step. LCMGM refers to the one produced from LGM, while the one synthesized using HGM is referred to as HCMGM. As displayed in Figure 1 (c) and (d), LCMGM was in the form of brown powder, while HCMGM was white. Both LCMGM and HCMGM have better solubility in water compared to native porang glucomannan (LGM and HGM) (Kobayashi et al., 2002).

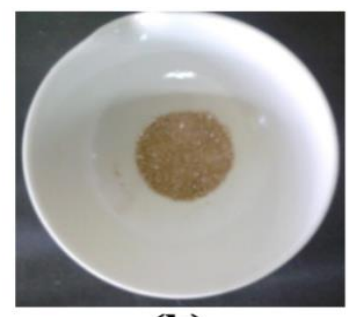

(b)

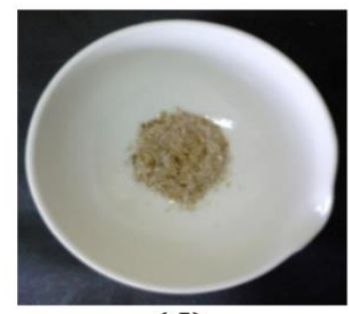

(d)

Figure 1. Glucomannan: (a) high viscosity glucomannan (HGM), (b) low viscosity glucomannan (LGM); Carboxymethyl glucomannan: (c) CMGM synthesized from HGM (HCMGM), (d) CMGM synthesized from LGM (LCMGM) 


\section{Characterization of Carboxymethyl Glucomannan FTIR Spectroscopy Analysis}

Both porang glucomannan and CMGM were examined their functional groups by FTIR, to confirm the formation of carboxymethyl group. The infrared spectra were recorded in the region of the wavenumber $4500-400 \mathrm{~cm}^{-1}$. Figure 2 displays the infrared spectra of both native porang glucomannan, LGM (Figure 2a) and HGM (Figure 2b), as well as CMGMs after synthesis, LCMGM (Figure 2c) and HCMGM (Figure 2d). As pointed out in blue and red circles in Figure 2, the increase in the intensity of the carbonyl absorption peak at wavenumbers of 1633 $\mathrm{cm}^{-1}$ and $1629 \mathrm{~cm}^{-1}$ confirms the formation of $\mathrm{C}=\mathrm{O}$ groups of $-\mathrm{COONa}$, which indicates that the carboxymethylation reaction was successful. The carboxymethylation reaction of glucomannan to CMGM was illustrated in Figure 3 (Wu, 2016 \& Xiao, 2015).

\section{Degree of Substitution}

The determination of degree of substitution (DS) was carried out to assess the level of carboxymethyl groups that have been successfully substituted in glucomannan during carboxymethylation process. DS value was calculated using Equation 1 as follows:

$$
D S=\frac{162 \times n_{\mathrm{COONa}}}{\mathrm{m}_{\mathrm{ds}}-80 \times \mathrm{n}_{\mathrm{COONa}}}
$$

where, $162 \mathrm{~g} / \mathrm{mol}$ is the molar mass of anhydroglucose unit; $80 \mathrm{~g} / \mathrm{mol}$ is the increase in the mass of anhydroglucose for the substitution of sodium carboxymethyl group; $\mathrm{m}_{\mathrm{ds}}$ is dry sample mass; and $\mathrm{n}_{\mathrm{COONa}}$ is the mole of COONa.

The value of DS acquired for each sample was summarized in Table 1. An increase in DS values of carboxymethyl glucomannan was observed compared to their native glucomannan before synthesis.
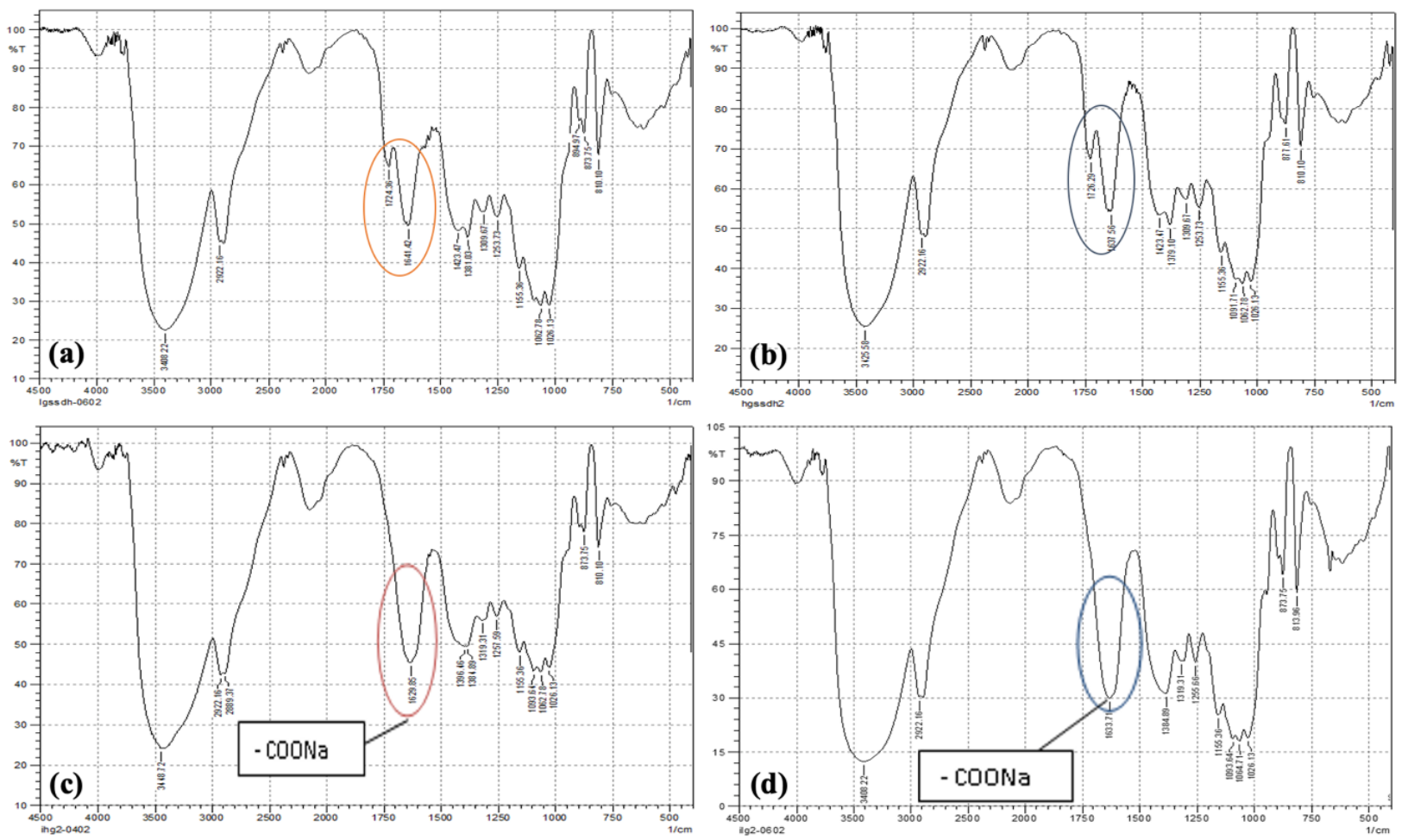

Figure 2. Infrared spectra of native Porang glucomannan: LGM (a); HGM (b), and their carboxymethylated modification (CMGM): LCMGM (c); HCMGM (d)

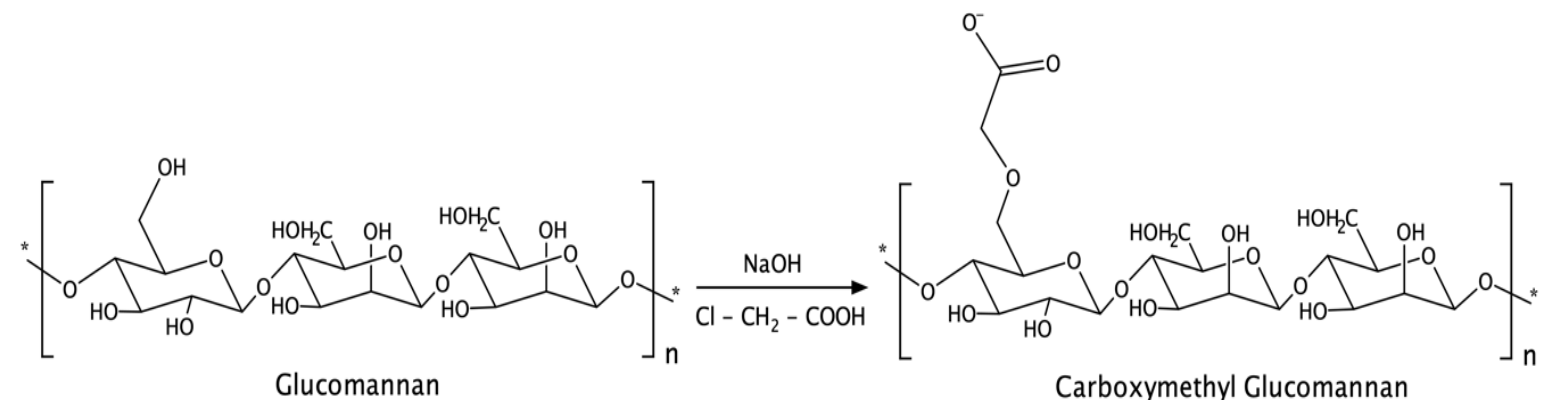

Figure 3. The carboxymethylation reaction of glucomannan 
Table 1. Degree of Substitution Value of Porang Glucomannan and CMGM

\begin{tabular}{cccc}
\hline \multicolumn{2}{c}{ Glucomannan } & \multicolumn{2}{c}{ Carboxymethyl Glucomannan } \\
\hline Sample & (DS) & Sample & (DS) \\
\hline HGM & 0.134 & HCMGM & 0.412 \\
LGM & 0.297 & LCMGM & 0.489 \\
\hline
\end{tabular}

\section{Metal Adsorption}

The effect of $\mathrm{pH}$, contact time, and metal concentration towards adsorption capacity of porang glucomannan and CMGM were also studied to acquired optimum adsorption conditions. The adsorption capacity was determined based on Equation 2 as follows:

$$
Q=\frac{V\left(C_{0}-C\right)}{W}
$$

where $C_{0}$ is the initial metal ion concentration before adsorption $(\mathrm{mg} / \mathrm{L}) ; \quad C$ is the final metal ion concentration after adsorption $(\mathrm{mg} / \mathrm{L}) ; \mathrm{V}$ is the total volume of solution (L); and $\mathrm{W}$ is the dry weight of adsorbent (g).

\section{Effect of $\mathrm{pH}$}

The effect of $\mathrm{pH}$ on the adsorption capacity of $\mathrm{Zn}^{2+}$ and $\mathrm{Cd}^{2+}$ ions was displayed in Figure 4. The experimental results show that the adsorption capacity is lower in low $\mathrm{pH}$ condition. This is because in acidic solutions with a low level of $\mathrm{pH}$, high concentrations of $\mathrm{H}_{3} \mathrm{O}^{+}$ions can promote protonation at the active site of adsorbent, causing most of the carboxymethyl group in the form of $\mathrm{COOH}$. This condition prevents metal ions from being adsorbed into CMGM, by reducing the attraction between metal ions and the surface of the adsorbent. Meanwhile, higher $\mathrm{pH}$ will cause $\mathrm{Zn}^{2+}$ and $\mathrm{Cd}^{2+}$ ions to precipitate in the form of $\mathrm{Zn}(\mathrm{OH})_{2}$ and $\mathrm{Cd}(\mathrm{OH})_{2}$, which can reduce the amount of metal ions adsorbed in CMGM, leading to an inaccurate measurement of adsorption. The optimum adsorption capacity was achieved at $\mathrm{pH} 6$ for both $\mathrm{Zn}^{2+}$ and $\mathrm{Cd}^{2+}$, according to Figure 4 .
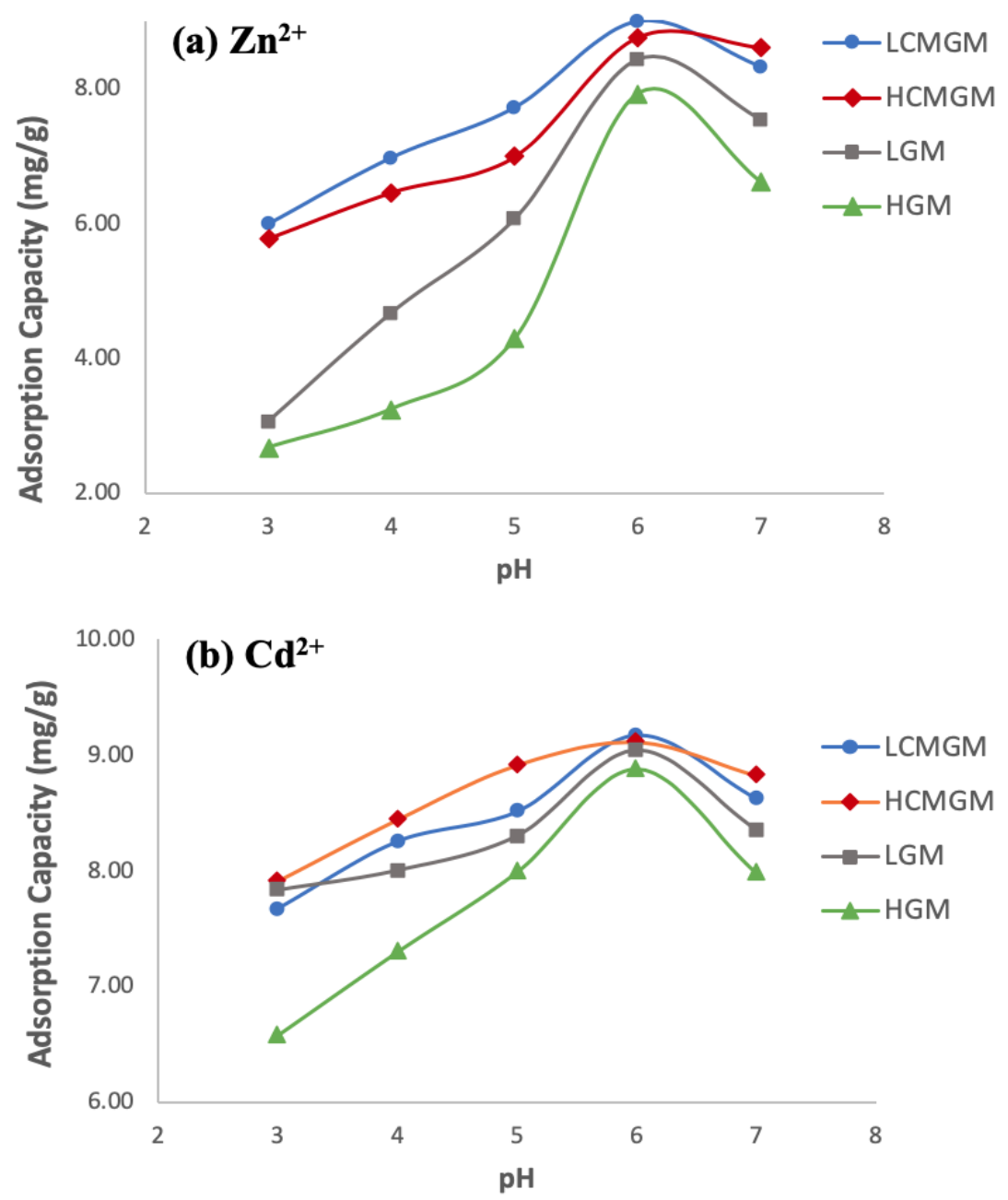

Figure 4. Effect of $\mathrm{pH}$ on the adsorption capacity $\mathrm{Zn}^{2+}(\mathbf{a})$ and $\mathrm{Cd}^{2+}(\mathbf{b})$ 


\section{Effect of Contact Time}

Figure 5 depicts the effect of contact time on the adsorption capacity of adsorbent. It shows that both ion $\mathrm{Cd}^{2+}$ and $\mathrm{Zn}^{2+}$ reaches equilibrium at 60 minutes, where the maximum adsorption capacity value was achieved. It can also be seen from the comparison of Figure $5(\mathbf{a})$ and (b), that the adsorption of $\mathrm{Cd}^{2+}$ into glucomannan and CMGM is faster than $\mathrm{Zn}^{2+}$.

\section{Effect of Metal Concentration}

The correlation between metal ion concentration and adsorption capacity is shown in Figure 6. Both graphs, each for $\mathrm{Cd}^{2+}$ and $\mathrm{Zn}^{2+}$, shared the same trend. Generally, the increase in the adsorption capacity was observed along with the increasing of metal ion concentration, until the maximum capacity was achieved. The maximum adsorption capacities of all adsorbent tested in this work for $\mathrm{Cd}^{2+}$ and $\mathrm{Zn}^{2+}$ in the range studied were listed in Table 2 . It can be derived from Table 2 that adsorbents with higher DS value have advantages in adsorbing more metal ions. Both modification of Porang glucomannan in the form of CMGMs are superior to native glucomannan in terms of metal adsorption capacity. This is because the functional groups responsible for the interaction between CMGM and metal ions is carboxyl (R-COOH) in carboxymethyl groups. Therefore, the adsorption will be more effective when the DS value of carboxymethyl groups is higher. Also, glucomannan with lower viscosity (LGM) show higher adsorption capacity than higher viscosity (HGM). This is due to the higher level of glucomannan in LGM $(25.93 \%)$ than those in HGM (21.41\%), that correspond to the higher value of DS and adsorption capacity.

According to the data listed in Table 2, DS value for LCMGM was the highest, followed by HCMGM, LGM, and HGM. Hence, the adsorption capacity of both $\mathrm{Cd}^{2+}$ and $\mathrm{Zn}^{2+}$ were also following the same trend.
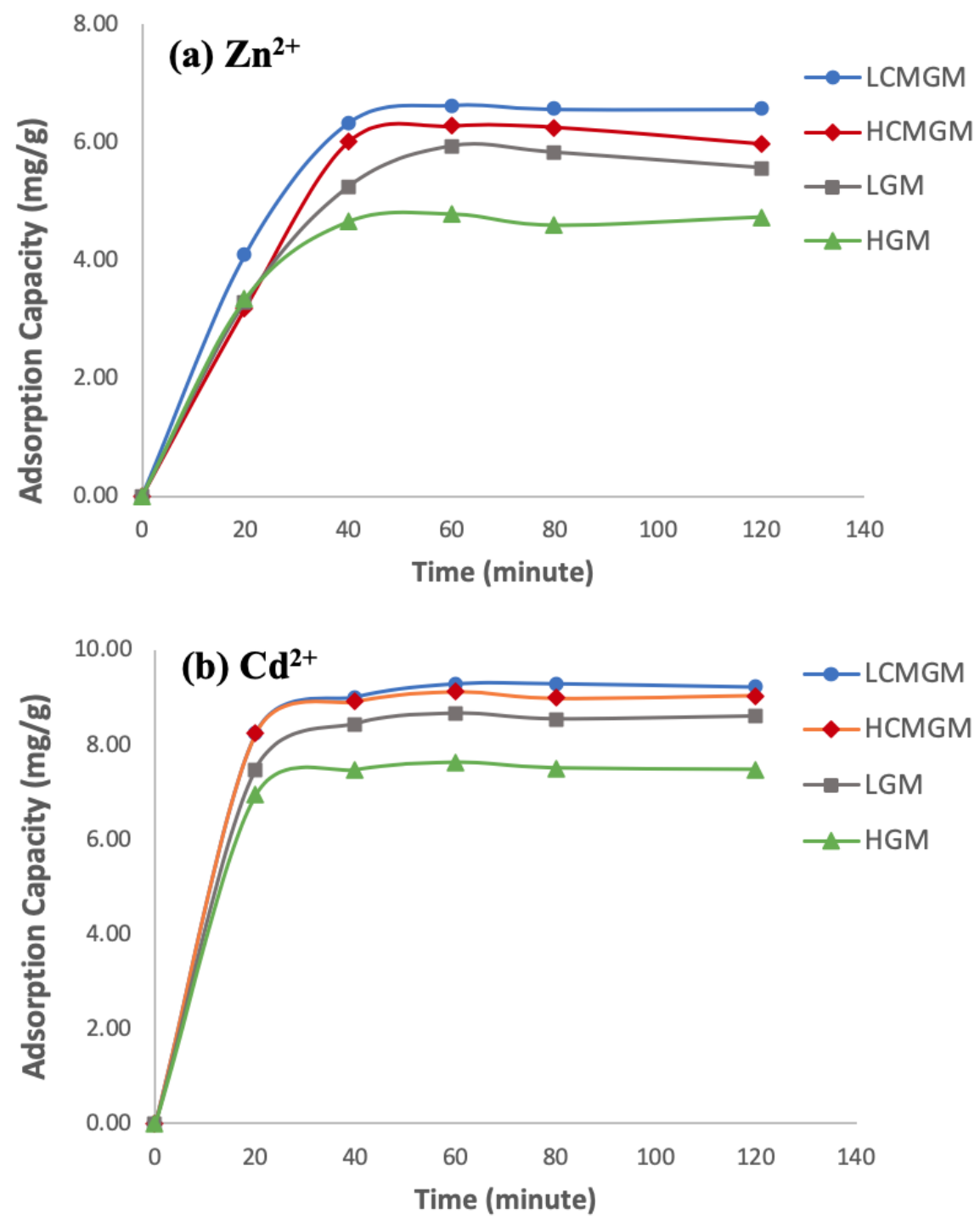

Figure 5. Effect of contact time on the adsorption capacity of $\mathrm{Zn}^{2+}(\mathbf{a})$ and $\mathrm{Cd}^{2+}(\mathbf{b})$ 

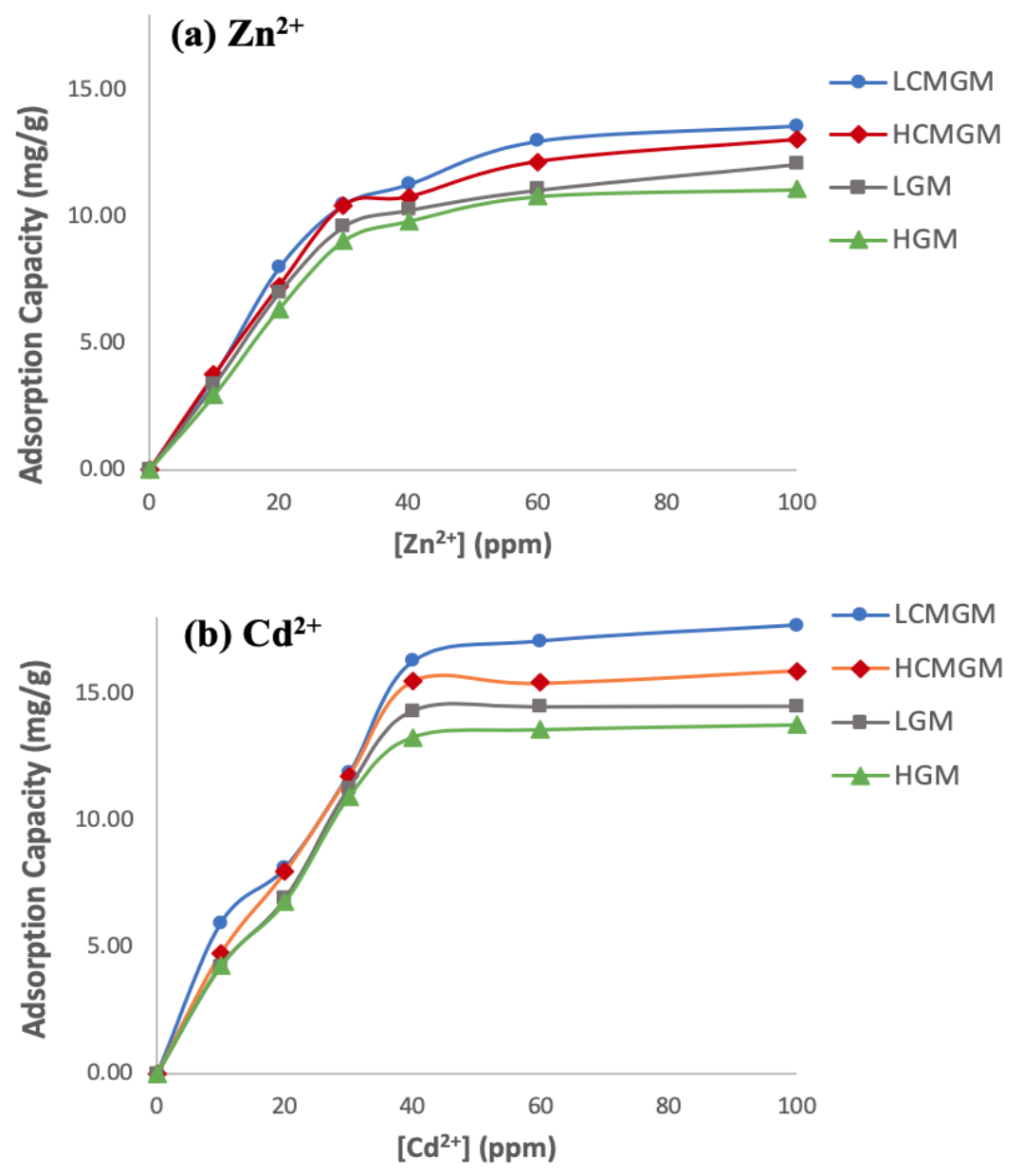

Figure 6. Effect of metal concentration on adsorption capacity of $\mathrm{Cd}^{2+}(\mathbf{a})$ and $\mathrm{Zn}^{2+}(\mathbf{b})$

Table 2. Maximum adsorption capacity of Porang Glucomannan and CMGM for $\mathrm{Cd}^{2+}$ and $\mathrm{Zn}^{2}$

\begin{tabular}{cccc}
\hline Sample & DS & $\mathrm{Cd}^{2+}(\mathrm{mg} / \mathrm{g})$ & $\mathrm{Zn}^{2+}(\mathrm{mg} / \mathrm{g})$ \\
\hline LGM & 0.297 & 14.50 & 12.08 \\
HGM & 0.134 & 13.76 & 11.06 \\
LCMGM & 0.489 & 17.70 & 13.61 \\
HCMGM & 0.412 & 15.90 & 13.04 \\
\hline
\end{tabular}

\section{Isothermal Adsorption}

The Langmuir and Freundlich isotherm adsorption data for the $\mathrm{Zn}^{2+}$ and $\mathrm{Cd}^{2+}$ ions against glucomannan and CMGM were shown in detail in Table 3. By comparing the correlation coefficients between Langmuir and Freundlich, it can be concluded that the adsorption of both metals in glucomannan and CMGM under the studied concentration range, follows Langmuir isotherm adsorption. This indicates that the adsorbent's (glucomannan and CMGM) surface where the adsorption sites are located is homogeneous, and the metal ions are adsorbed according to ion exchange mechanism by forming a single layer (monolayer).

In native glucomannan before modification process, metal ions interact with hydroxyl group (R$\mathrm{OH})$ as the adsorption sites. Meanwhile, after modification into CMGM, the functional group responsible for metal ions adsorption is carboxyl functional groups (R-COOH). $\mathrm{H}^{+}$in carboxyl groups are easier to be substituted by positive metal ions than hydroxyl groups. Therefore, the modification of native glucomannan into CMGM increase the monolayer adsorption capacity $\left(Q_{m}\right)$ for both $\mathrm{Zn}^{2+}$ and $\mathrm{Cd}^{2+}$.

These data give an overview of the metal adsorption capacity of $\mathrm{Zn}^{2+}$ and $\mathrm{Cd}^{2+}$ in both glucomannan and CMGM from Porang plant, that have never been reported yet. Moreover, the adsorption capacity of $\mathrm{Zn}^{2+}$ and $\mathrm{Cd}^{2+}$ in more common glucomannan and CMGM, which is derived from Konjac plant, have also not been much studied yet. A study reported the maximum adsorption capacity $\left(Q_{m}\right)$ of carboxymethyl konjac glucomannan (CMKGM) for $\mathrm{Cd}^{2+}$ was $23.6 \mathrm{mg} / \mathrm{g}$ (Niv et al., 2007). This is comparable with the result of Porang CMGM ini this study, which is $18.87 \mathrm{mg} / \mathrm{g}$ for $\mathrm{Cd}^{2+}$. 
Table 3. Isotherm Adsorption Langmuir and Freundlich

\begin{tabular}{|c|c|c|c|c|c|c|c|}
\hline \multirow{2}{*}{ Metal } & \multirow{2}{*}{ Sample } & \multicolumn{3}{|c|}{ Langmuir } & \multicolumn{3}{|c|}{ Freundlich } \\
\hline & & $b(\mathrm{~L} / \mathrm{g})$ & $Q_{m}(\mathrm{mg} / \mathrm{g})$ & $R^{2}$ & $n(g / L)$ & $K_{f}(\mathrm{mg} / \mathrm{g})$ & $\mathrm{R}^{2}$ \\
\hline \multirow[t]{4}{*}{$\mathrm{Zn}$} & LGM & 1.029 & 13.70 & 0.991 & 2.49 & 2.52 & 0.777 \\
\hline & HGM & 1.017 & 12.82 & 0.979 & 2.26 & 2.03 & 0.753 \\
\hline & LCMGM & 1.042 & 15.38 & 0.992 & 2.55 & 3.02 & 0.774 \\
\hline & HCMGM & 1.039 & 14.71 & 0.994 & 2.58 & 2.91 & 0.806 \\
\hline \multirow[t]{4}{*}{$\mathrm{Cd}$} & LGM & 1.054 & 16.39 & 0.983 & 2.51 & 3.31 & 0.767 \\
\hline & HGM & 1.055 & 15.38 & 0.987 & 2.62 & 3.3 & 0.796 \\
\hline & LCMGM & 1.078 & 18.87 & 0.986 & 4.20 & 6.8 & 0.844 \\
\hline & HCMGM & 1.070 & 17.24 & 0.993 & 3.30 & 4.19 & 0.812 \\
\hline
\end{tabular}

Table 4. Adsorption and Desorption Cycles

\begin{tabular}{cccccc}
\hline \multirow{2}{*}{ Sample } & \multirow{2}{*}{ Repetition } & \multicolumn{2}{c}{$\mathrm{Zn}^{2+}$} & \multicolumn{2}{c}{$\mathrm{Cd}^{2+}$} \\
\cline { 2 - 6 } & 1 & $\mathrm{~A}(\mathrm{mg} / \mathrm{g})$ & $\mathrm{D}(\%)$ & $\mathrm{A}(\mathrm{mg} / \mathrm{g})$ & $\mathrm{D}(\%)$ \\
\hline LGM & 1 & 12.02 & 88.37 & 14.59 & 90.70 \\
& 2 & 11.70 & 88.14 & 12.65 & 89.32 \\
& 3 & 11.59 & 89.85 & 13.92 & 90.37 \\
\hline HGM & 1 & 10.95 & 88.68 & 13.70 & 88.84 \\
& 2 & 10.52 & 88.71 & 13.39 & 85.76 \\
& 3 & 11.05 & 86.16 & 12.88 & 87.46 \\
\hline LCMGM & 1 & 13.43 & 90.89 & 17.77 & 91.61 \\
& 2 & 12.77 & 92.68 & 16.40 & 91.49 \\
HCMGM & 3 & 12.97 & 90.92 & 17.08 & 89.90 \\
& 1 & 12.92 & 91.04 & 15.93 & 91.37 \\
& 2 & 12.96 & 92.67 & 15.07 & 90.20 \\
& 3 & 12.68 & 90.53 & 15.48 & 90.37 \\
\hline
\end{tabular}

\section{Metal Desorption and Regeneration of CMGM}

Metal ions adsorbed by glucomannan and CMGM were released (desorption) using $\mathrm{HNO}_{3} \quad 0.1 \mathrm{M}$. This experiment was carried out to determine the reusability of both glucomannan and CMGM in metal adsorption. Desorption percentage of metal ions were estimated according to the following Equation 3:

$$
D=\frac{m_{\text {des }}}{m_{\text {ads }}} \times 100 \%
$$

where, $m_{d s}$ is the number of metal ions desorbed $(\mathrm{mg})$ and $m_{\text {ads }}$ is the number of metal ions adsorbed $(\mathrm{mg})$.

The adsorption and desorption data displayed in Table 4 shows that both Porang glucomannan and CMGM can be repeatedly regenerated without significantly affecting their adsorption capacity. In addition, both Porang glucomannan and CMGM have a high desorption percentage for both metal ions tested in this study.

\section{CONCLUSIONS}

Carboxymethyl glucomannan (LCMGM and HCMGM) from Porang plant (A. oncophyllus) has been successfully synthesized from the reaction of Porang glucomannan (LGM and HGM) with monochloroacetic acid at $60^{\circ} \mathrm{C}$ for 3 hours under $\mathrm{pH}$ 9-10. FTIR results confirm the formation of $-\mathrm{COONa}$ groups, indicating that carboxymethylation reaction was accomplished. The degree of substitution (DS) obtained for LCMGM and HCMGM were 0,489 and
0,412 , respectively. This study also shows that metal adsorption capacity of both Porang glucomannan and CMGM were affected by $\mathrm{pH}$, contact time, and initial concentration of the metal. The optimum conditions for the adsorption of $\mathrm{Zn}$ and $\mathrm{Cd}$ ions were achieved at $\mathrm{pH} 6$ with 60 minutes contact time. The maximum adsorption capacity of LCMGM was $13.61 \mathrm{mg} / \mathrm{g}$ and $17.70 \mathrm{mg} / \mathrm{g}$ for $\mathrm{Zn}$ and $\mathrm{Cd}$, respectively. While the maximum adsorption capacity of HCMGM was slightly lower at $13.04 \mathrm{mg} / \mathrm{g}$ and $15.09 \mathrm{mg} / \mathrm{g}$ for the same metal ions. This indicates that adsorbent with higher DS value, has better adsorption capacity. It can also be concluded that the adsorption of $\mathrm{Zn}$ and $\mathrm{Cd}$ into Porang glucomannan and CMGM follows Langmuir isotherm adsorption. Adsorbent regeneration studies show that both Porang glucomannan and CMGM can be used repeatedly, without significantly affecting the adsorption capacity and desorption percentage.

\section{ACKNOWLEDGEMENTS}

This research did not receive any specific grant from funding agencies in the public, commercial, or not-for-profit sectors. All authors contributed equally to this work.

\section{REFERENCES}

Alonso-Sande, M., Teijeiro-Osorio, D., RemuñánLópez, C., \& Alonso, M. J. (2009). Glucomannan, a promising polysaccharide for 
biopharmaceutical purposes. European Journal of Pharmaceutics and Biopharmaceutics, 72(2), 453-462.

An, N. T., Dong, N. T., Dung, P. Le, \& Thien, D. T. (2011). Synthesis and characterization of watersoluble O-carboxymethyl glucomannan derivatives. Carbohydrate Polymers, 83(2), 645-652.

Battacone, G., Carboni, G. A., Nicolussi, P., Ligios, C., \& Pulina, G. (2007). Use of a glucomannan polymer to reduce the effects of mycotoxincontaminated diets in finishing pigs. Italian Journal of Animal Science, 6(sup 1), 673-675.

Behera, S. S., \& Ray, R. C. (2017). Nutritional and potential health benefits of konjac glucomannan, a promising polysaccharide of elephant foot yam, Amorphophallus konjac K. Koch: A review. Food Reviews International, 33(1), 22-43.

Chen, J., Zhang, W., \& Li, X. (2016). Adsorption of $\mathrm{Cu}(\mathrm{II})$ ion from aqueous solutions on hydrogel prepared from Konjac glucomannan. Polymer Bulletin, 73(7), 1965-1984.

Chen, P., Zhang, H., Ding, J., Lin, X., Lu, X., Liu, C., \& Tang, Y. (2017). Carboxylmethyl konjac glucomannan conjugated polydopamine composites for $\mathrm{Pb}(\mathrm{II})$ removal. Carbohydrate Polymers, 162, 62-70.

Chen, T., Shi, P., Zhang, J., Li, Y., Duan, T., Dai, L., ... Zhu, W. (2018). Natural polymer konjac glucomannan mediated assembly of graphene oxide as versatile sponges for water pollution control. Carbohydrate Polymers, 202, 425433.

Chua, M., Chan, K., Hocking, T. J., Williams, P. A., Perry, C. J., \& Baldwin, T. C. (2012). Methodologies for the extraction and analysis of konjac glucomannan from corms of Amorphophallus konjac K. Koch. Carbohydrate Polymers, 87(3), 2202-2210.

Fu, F., \& Wang, Q. (2011). Removal of heavy metal ions from wastewaters: A review. Journal of Environmental Management, 92(3), 407-418.

Harmayani, E., Aprilia, V., \& Marsono, Y. (2014). Characterization of glucomannan from Amorphophallus oncophyllus and its prebiotic activity in vivo. Carbohydrate Polymers, 112, 475-479.

Huang, D., Gong, X., Liu, Y., Zeng, G., Lai, C., Bashir, H., ... Wan, J. (2017). Effects of calcium at toxic concentrations of cadmium in plants. Planta, 245(5), 863-873.

Jain, N., Johnson, T. A., Kumar, A., Mishra, S., \& Gupta, N. (2015). Biosorption of Cd (II) on jatropha fruit coat and seed coat. Environmental Monitoring and Assessment, 187(7), 411.

Jobby, R., Jha, P., Yadav, A. K., \& Desai, N. (2018). Biosorption and biotransformation of hexavalent chromium [Cr(VI)]: A comprehensive review. Chemosphere, 207, 255-266.

Kobayashi, S., Tsujihata, S., Hibi, N., \& Tsukamoto, Y. (2002). Preparation and rheological characterization of carboxymethyl konjac glucomannan. Food Hydrocolloids, 16(4), 289 294.

Liang, L., Lin, X., Liu, Y., Sun, S., Chu, H., Chen, Y., ... Shang, R. (2020). Carboxymethyl konjac glucomannan mechanically reinforcing gellan gum microspheres for uranium removal. International Journal of Biological Macromolecules, 145, 535-546.

Liu, B., Zhang, L., \& Wang, H. (2011). Study of adsorption of heavy metal ions onto new type resin. 2011 International Conference on Remote Sensing, Environment and Transportation Engineering, 7855-7858.

Liv, F., Luo, X. G., \& Lin, X. Y. (2009). Removal of Zn (II) from Aqueous Solution by Copolymer of Grafting Acrylic Acid onto Deacetylated Konjac Glucomannan. Materials Science Forum, 620, $611-614$.

Liv, F., Luo, X., Lin, X., Liang, L., \& Chen, Y. (2009). Removal of copper and lead from aqueous solution by carboxylic acid functionalized deacetylated konjac glucomannan. Journal of Hazardous Materials, 171(1), 802-808.

Luo, X., Liv, F., Deng, Z., \& Lin, X. (2011). Removal of copper(II) from aqueous solution in fixed-bed column by carboxylic acid functionalized deacetylated konjac glucomannan. Carbohydrate Polymers, 86(2), 753-759.

Mangold, S., Potrykus, J., Björn, E., Lövgren, L., \& Dopson, M. (2013). Extreme zinc tolerance in acidophilic microorganisms from the bacterial and archaeal domains. Extremophiles, 17(1), 75-85.

Mao, J., Li, S., He, C., Tang, Y., Chen, Z., Huang, J., \& Lai, Y. (2019). Robust amphiprotic konjac glucomannan cross-linked chitosan aerogels for efficient water remediation. Cellulose, 26(11), 6785-6796.

Mukherjee, S., \& Halder, G. (2018). A review on the sorptive elimination of fluoride from contaminated wastewater. Journal of Environmental Chemical Engineering, 6(1), 1257-1270.

Niu, C. M., Li, S. Y., \& Huang, D. (2011). Adsorption of $\mathrm{Cu}$ (II) lons from an Aqueous Solution by Cross-Linked Carboxymethyl Konjac Glucomannan. Advanced Materials Research, 239-242, 2310-2316.

Niu, C., Wu, W., Wang, Z., Li, S., \& Wang, J. (2007). Adsorption of heavy metal ions from aqueous solution by crosslinked carboxymethyl konjac glucomannan. Journal of Hazardous Materials, $141(1), 209-214$.

Parry, J. M. (2010). Konjac Glucomannan. In A. Imeson (Ed.), Food Stabilisers, Thickeners and 
Gelling Agents (pp. 198-216). England: A John Willey \& Sons, Ltd.

Roney, N., Osier, M., Paikoff, S. J., Smith, C. V, Williams, M., \& De Rosa, C. T. (2006). ATSDR evaluation of the health effects of zinc and relevance to public health. Toxicology and Industrial Health, 22(10), 423-493.

Salah, T. A., Mohammad, A. M., Hassan, M. A., \& ElAnadouli, B. E. (2014). Development of nanohydroxyapatite/chitosan composite for cadmium ions removal in wastewater treatment. Journal of the Taiwan Institute of Chemical Engineers, 45(4), 1571-1577.

Stojanović, Ž., Jeremić, K., Jovanović, S., \& Lechner, M. D. (2005). A Comparison of Some Methods for the Determination of the Degree of Substitution of Carboxymethyl Starch. Starch Stärke, 57(2), 79-83.

Sud, D., Mahajan, G., \& Kaur, M. P. (2008). Agricultural waste material as potential adsorbent for sequestering heavy metal ions from aqueous solutions - A review. Bioresource Technology, 99(14), 6017-6027.

Wan Ngah, W. S., \& Hanafiah, M. A. K. M. (2008). Removal of heavy metal ions from wastewater by chemically modified plant wastes as adsorbents: A review. Bioresource Technology, 99(10), 3935-3948.

Wang, C., Zhu, Y. P., Xu, M., Qiao, Y., \& Zhang, W. H. (2011). An Improvement of the Preparation Method of Carboxymethyl Konjac Glucomannan. Applied Mechanics and
Materials, 52-54, 1340-1343.

Wu, L., Lin, X., Wu, J., Zhou, X., \& Luo, X. (2016). Adsorption behavior of carboxymethyl konjac glucomannan microspheres for fluoride from aqueous solution. RSC Advances, 6(92), 89417-89429. https://doi.org/10.1039/C6RA17183D

Xia, B., Ha, W., Meng, X.-W., Govender, T., Peng, S.L., Ding, L.-S., ... Zhang, S. (2010). Preparation and characterization of a poly(ethylene glycol) grafted carboxymethyl konjac glucomannan copolymer. Carbohydrate Polymers, 79(3), 648654.

Xiao, M., Dai, S., Wang, L., Ni, X., Yan, W., Fang, Y., ... Jiang, F. (2015). Carboxymethyl modification of konjac glucomannan affects water binding properties. Carbohydrate Polymers, 130, 1-8. https://doi.org/https://doi.org/10.1016/j.carbp ol.2015.05.001

Yadav, V. B., Gadi, R., \& Kalra, S. (2019). Clay based nanocomposites for removal of heavy metals from water: A review. Journal of Environmental Management, 232, 803-817.

Zawierucha, I., Kozlowski, C., \& Malina, G. (2016). Immobilized materials for removal of toxic metal ions from surface/groundwaters and aqueous waste streams. Environ. Sci.: Processes Impacts, 18(4), 429-444.

Zewail, T. M., \& Yousef, N. S. (2015). Kinetic study of heavy metal ions removal by ion exchange in batch conical air spouted bed. Alexandria Engineering Journal, 54(1), 83-90. 